\title{
EVALUATION OF COLLAPSE MECHANISMS IN MASONRY BUILDINGS: CRITICAL OVERVIEW AND CASE HISTORIES
}

\author{
VALUACIÓN DE LOS MECANISMOS DE COLAPSO EN LOS EDIFICIOS DE \\ MAMPOSTERÍA: VISIÓN GENERAL CRIITICA E HISTORIAS DE CASOS
}

\section{ANGELO DI TOMMASO', SUSANNA CASACCI ${ }^{2}$}

1 University of Bologna. Italia. angelo.ditommaso@unibo.it

2 University of Bologna. Italia. susanna.casacci2@unibo.it

RESUMEN

En los últimos años el enfoque para el análisis de la vulnerabilidad sísmica de los edificios de mampostería considera crucial la evaluación de posibles mecanismos locales. Las líneas de "fractura" representadas en la pared (cuando es "compacta") pueden mostrar su estado lábil de equilibrio y señalar la cinemática potencial del movimiento relativo entre bloques. La evaluación analítica de la cinemática, lineal y no lineal, presenta algunos aspectos que pueden ser analizados con crítica.

Entre las técnicas para contrastar los mecanismos potenciales podrían considerarse algunas muy eficaces: aplicar placas o bandas de materiales compuestos (recubiertos por yeso) o el refuerzo adicional.

Se consideran en detalle los criterios básicos para aplicarlo y los procedimientos analíticos para determinar el nivel de mejora.

Este trabajo analizará algunos de estos aspectos con referencia a casos reales de estudio (teatro de Pavarotti y la Iglesia de San Barnaba en Módena, y campanario en Reno Centese, Ferrara, Italia).

PALABRAS CLAVE:
In recent years the approach to the analysis of seismic vulnerability of masonry buildings considers as crucial the evaluation of potential local mechanisms. The "fracture" lines depicted on the wall (when it is "compact") can show its labile condition of equilibrium and point out the potential kinematic of relative motion among blocks. The analytical evaluation of kinematics, linear and non-linear, presents some aspects that could be analysed with criticism.

Among the techniques to contrast the potential mechanisms some very effective ones could be considered: plating with composites (covered by plaster) or reinforced re-pointing.

Basic criteria to apply it and analytical procedures to determine the level of upgrading are considered in detail.

This paper will analyse some of these aspects with reference to actual cases of study (Pavarotti theatre and San Barnaba Church in Modena, and campanile in Reno Centese, Ferrara, Italy).

KEYWORDS: historic masonry, FRCM, capacity curve, collapse mechanism, composite material. 
INTRODUCTION

In this paper, we want to consider compact masonry buildings, then excluding "multiple leaves masonry" because the former presents its peculiar mechanisms of collapse during earthquake, different from the case of compact masonry. Here for "compact" we intend that masonry in which no lack of continuity is present within the thickness. Therefore, we can consider homogeneity at macro-level.

When an event (earthquake, tornado...) breaks the wall in different compact blocks, they stands in equilibrium until the mutual constraints reaches (evolving the configuration under loading), theipo-static (labile) condition of the structure. That is the internal and external constrains are not sufficient, in number or in position, to guarantee the equilibrium of the structure.

Some examples: 1) one constraint does not obstruct the movement allowed by all the other constraints, 2) the centres of rotation (absolute and relative) became aligned, as critical configuration.

The analysis is linear when is considered only the act of motion of blocks; this is a fundamental aspect for the application of principle of virtual work to evaluate the multiplier of loads.

When the analysis is devoted to the actual state of the structures, the Italian standard NTC$2008[1,5]$ allows to consider the introduction of a) factor of confidence, b) a safety factor in addition to the nominal compressive strength. These factors are important in the design of structures, but not for the investigation of the actual state of the structure under external actions.

In any case, two procedures can be followed: a) linear or b) non-linear kinematic analysis, but in both cases the first step is to evaluate the "multiplier of loads" (corresponding to the activation of the mechanism).

After the analysis of vulnerability, a strengthening intervention should be considered in all the cases that cannot be accepted regarding the expected loading conditions. In the field of Historic Constructions, among the possible interventions respecting the dominant cultural position we have to consider the use of appropriate technique of composite materials. Two effective techniques are nowadays on special attention in Italy [7]: a) plating and b) reinforced repointing [2,3]. In both cases the material used is composite FRCM (Fabric Reinforced Cementitious Material) in which the matrix is inorganic, and reinforcement is a fabric made with fibres (Basalt, Aramid, Carbon, PBO, galvanized steel wires,...). These techniques act to produce crack arrestors and then inhibitors to the potential mechanisms, reducing the vulnerability.

KINEMATIC PROCEDURES AND CRITICISMS

The evaluation of potential local mechanisms is one of the most commonly used approaches to study the vulnerability of masonry buildings. In accordance with Italian Codes [1, 5, 18], the local mechanisms can be studied by using different analysis: linear static analysis, non-linear static analysis, linear kinematic analysis, nonlinear kinematic analysis. The aim of this paper is to focus on the kinematic approaches applied to compact masonry buildings.

The usual assumptions at the base of the kinematic analysis are [18]:

1. compressive strength of masonry is infinite;

2. tensile strength of masonry is close to zero;

3. no sliding between blocks can occur.

The kinematic approach and the so called capacity curve method $[11,12,14,15]$, can be linear or non-linear, and is based on the determination of the horizontal action that the structure can sustain during the evolution of the collapse mechanism.

The main steps of the procedure are:

1. identification of a collapse mechanism;

2. definition of the position of the control point $(\mathrm{CP})$;

3. evaluation of the multiplier of the horizontal loads $\alpha 0$ that activates the mechanism by using the principle of virtual works (Eq. 1):

$$
\begin{aligned}
& \alpha_{0}\left(\sum P_{i} \delta_{x, i}+\sum P_{j} \delta_{x, j}\right) \\
& -\sum P_{i} \delta_{x, j}-\sum F_{h} \delta_{h}=L_{f i}
\end{aligned}
$$

where $\alpha 0$ is the multiplier of the horizontal loads, $\mathrm{P}$ are the quantities function of the weights, $\delta$ are the

virtual displacements;

4. curve of the multiplier of the loads vs. displacement of CP;

5. calculation of the spectral acceleration (Eq. 2) and consequently the spectral displacement (Eq. 3):

$a_{0}^{*}=\frac{\alpha_{0} \Sigma P_{i}}{M^{*} F C}$ 


$$
d^{*}=d_{K} \frac{\Sigma P_{x i} \delta_{x, i}^{2}}{F C \delta_{x, k} \Sigma P_{x i} \delta_{x, i}}
$$

where $M^{*}$ is the participating mass during the mechanism, FC is the factor of confidence;

6. plot of the capacity curve (spectral acceleration vs. spectral displacement).

The control point CP should be representative of all the mechanisms analysed and, generally, is located [4] on the top floor of the structure or in the floor where there is a higher concentration of mass with relevant displacements.

The difference between linear and non-linear approach can have influence on the verification results: in the linear approach the verification is made in terms of spectral acceleration, while in the non-linear analysis is in terms of displacement.

In other words, the linear kinematic analysis is based on the determination of the resistance of the system with regard to the horizontal acceleration that activates the local mechanism. This approach is in terms of force and a behaviour factor, $\mathrm{q}>1$, is introduced [1] to decrease the demand in dependency to estimated ductility effects of the masonry structure. The coefficient $\mathrm{q}$ is recommended by standards but is dependent on the geometry and material consistency of structure.

Thenon-linearkinematicapproach, isinterms of displacement and is based on a comparison between the ultimate displacement capacity of the structure, $\mathrm{du}^{*}$, and the displacement demand of the earthquake, $\Delta d[11,14]$.

Starting from the dynamic characteristics of the equivalent S.D.O.F. system, the capacity curve is defined as the relation between the base shear vs. horizontal displacement of the control point $\mathrm{CP}$, identified on the structure.

The spectral displacement $\mathrm{d}^{*}$ of the S.D.O.F. system during the mechanism is obtained multiplying at each step the displacement dk by a quantity function of the weights $\mathrm{Pi}$ and virtual displacements $\delta x . \mathrm{i}$, starting from the initial configuration $[1,5,18]$. The intersection between the capacity curve and the elastic spectrum (in terms of displacements and acceleration) identifies the so called performance point that provides information about the safety of the structure.

Many literature studies deal with the application of the non linear kinematic approach, and two crucial outcomes are [4]:
(1) the choice of CP doesn't affect so much the trend of the capacity curve; (2) the capacity curve can be approximated as a straight line.

The crucial points of the procedures can be evaluated on the case of study, where the applications give evidence of the peculiarities.

\section{CASE STUDY \\ SAN BARNABA CHURCH IN MODENA: IN PLANE COLLAPSE OF \\ FAÇADE}

The façade of San Barnaba Church (figure. 1) is one of the most important macro-elements that can be identified and studied in the context of collapse mechanism on this building.
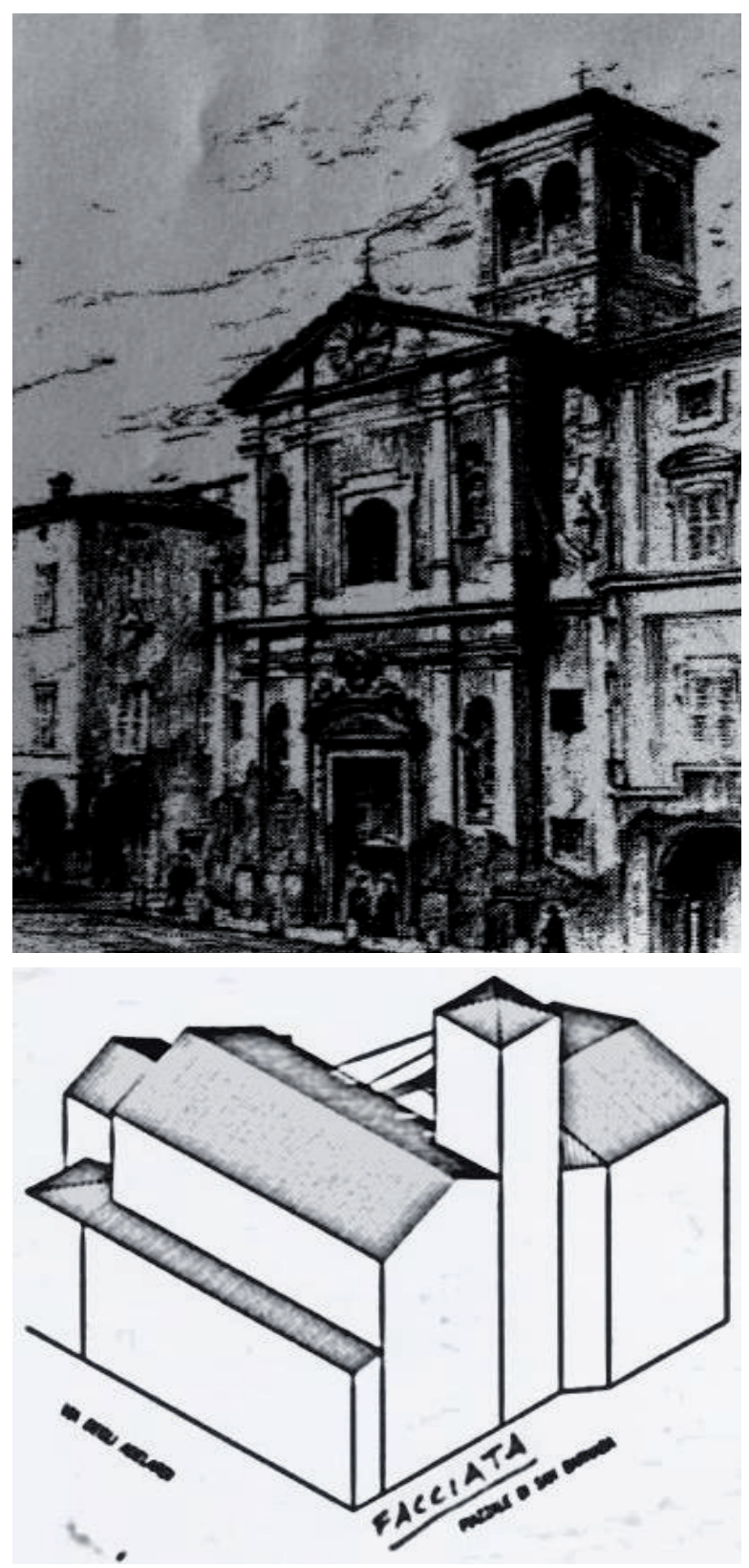

Figure 1. a) The façade of San Barnaba Church and b) its simplified geometrical model. 
A dominant in plane mechanism of the façade (figure 2) is due to the formation of an inclined crack that starts from the top right corner of the window and goes to the top left corner of the main door.

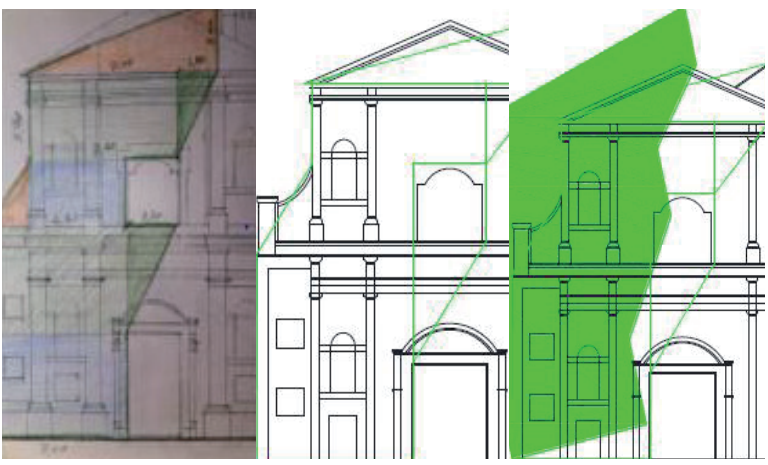

Figure 2. Collapse of the façade of San Barnaba Church: in plane rotation of left section.

Following the linear kinematic approach described in Section 2, the multiplier of the loads (Eq. 1) and the spectral acceleration that activates the mechanism (capacity of the system) (Eq. 2) are calculated. In order to have information about the safety of the structure with respect to the mechanism under consideration, a ratio $\mathrm{R}$ (Eq.4) between the capacity and demand in terms of acceleration is introduced.

$$
R=\frac{a_{o}^{*}}{a_{d}^{*}} \gtreqless 1
$$

If $\mathrm{R}$ is major than 1 the verification is considered satisfied, otherwise reinforcements are needed.

In this present case, taking into account a behaviour factor $\mathrm{q}=2.25$ for un-reinforced masonry structures, following suggestion in [5], the spectral acceleration (demand) is evaluated and the structure is in safety conditions against the collapse of the façade as local mechanism.

In table 1 the results of un- reinforced structure are collected.

TABLE 1. RESULTS OF LINEAR KINEMATIC ANALYSIS FOR NOT REINFORCED STRUCTURE

\begin{tabular}{rrrr}
$\mathbf{A}_{\mathbf{0}}$ & $\mathbf{A}_{\mathbf{0}}^{*}$ & $\mathbf{A}_{D}^{*}$ & $R$ \\
0.568 & $0.554 \mathrm{~g}$ & $0.322 \mathrm{~g}$ & 1.72 \\
\hline
\end{tabular}

If we want to increase the stability, we can insert, for example, three GeoSteel600 strips Kerakoll (figure 3), that are FRCM with steel wire fabrics, under the plaster, to contrast potential Mode I opening.

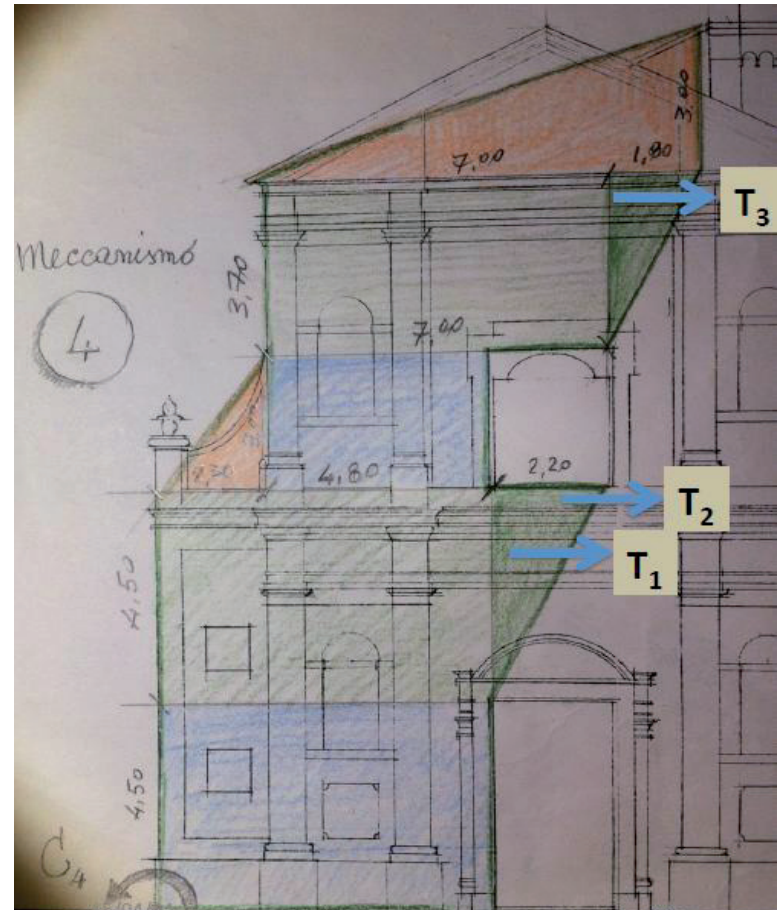

Figure 3. Three GeoSteel600 strips to contrast the in plane collapse of the facade.

In this case, considering reinforced masonry, the contribution of strips and a revised behaviour factor q equal to 2.70 as suggested in [5], should be added in the evaluation of the multiplier of loads, the capacity, the demand and, consequently, the ratio between capacity and demand are updated.

In table 2, the results for the reinforced structure are shown.

\section{TABLE 2. RESULTS OF LINEAR KINEMATIC ANALYSIS FOR REINFORCED} STRUCTURE

\begin{tabular}{rrrr}
$\mathbf{A}_{\mathbf{0}}$ & $\mathbf{A}_{0}^{*}$ & $\mathbf{A}_{D}^{*}$ & $R$ \\
0.593 & $0.579 \mathrm{~g}$ & $0.268 \mathrm{~g}$ & 2.16 \\
\hline
\end{tabular}

\section{EVALUATION OF "CRACK CLOSING EFFECT" DUE TO COMPOSITE STRIP PLATING}

One important aspect in the design of FRCM as strengthening materials is the evaluation of the detachment force of the fabric strip from masonry, taking into account mechanical connectors (Eq.5):

$$
F_{\max }=\sqrt{N_{0}^{2}+2 b_{f}^{2} E_{f} t_{f} \Gamma}
$$

where N0 is the maximum force of the connector, bf, Ef and tf are the width, the elastic modulus and the thickness of the strip, respectively; $\Gamma$ is the fracture energy of brick [9].

The maximum force of the connector can be calculated [9] by using Eq. 6: 


$$
N_{0}=\frac{1}{c} A E_{c} \varepsilon_{o}
$$

with $\mathrm{A}$ is the effective area (generally is the $30 \%$ of the total area of the connector, it depends by the technology of application), Ec and $\varepsilon 0$, are the elastic modulus and the ultimate strain of the connector, respectively; $\mathrm{c}$ is the reduction coefficient due to bending of the wires composing the connector.

With the aim to evaluate the effective adherence length of GeoSteel600, Eq. 7 can be used:

$$
L_{e f f}=\sqrt{\frac{E_{f} t_{f} 1}{2 f_{c t m}}}
$$

where fctm is the mean tensile strength of masonry, (tf xl) is the transversal area of the fabric whose width is unitary. Considering tf equal to $0.084 \mathrm{~mm}$, Ef equal to $190 \mathrm{GPa}, 1.5 \%$ as $\varepsilon 0$, 1.5 as $\mathrm{c}$ and $\Gamma$ equal to $0.024 \mathrm{Nmm}-1$, in table 3 the detachment force of the strip, the maximum force of the connectors and the effective length are shown.

TABLE 3. CHARACTERISTICS OF FABRIC GEOSTEEL600.

\begin{tabular}{rrr}
$\mathbf{F}_{\mathrm{MAX}}[\mathbf{K N}]$ & $\mathbf{N}_{0}[\mathbf{K N}]$ & $\mathbf{L}_{\mathrm{BFF}}[\mathbf{M M}]$ \\
11 & 7 & 160 \\
\hline
\end{tabular}

All these elements can be utilized for a correct design of the proposed three reinforcing FRCM strips,

3.3 Pavarotti Theatre: collapse of rear wall (stage volume)

The Pavarotti Theatre (figures.4a and 4b) is located in Modena city centre, Italy, and was built in 1841 by the architect F. Vandelli.

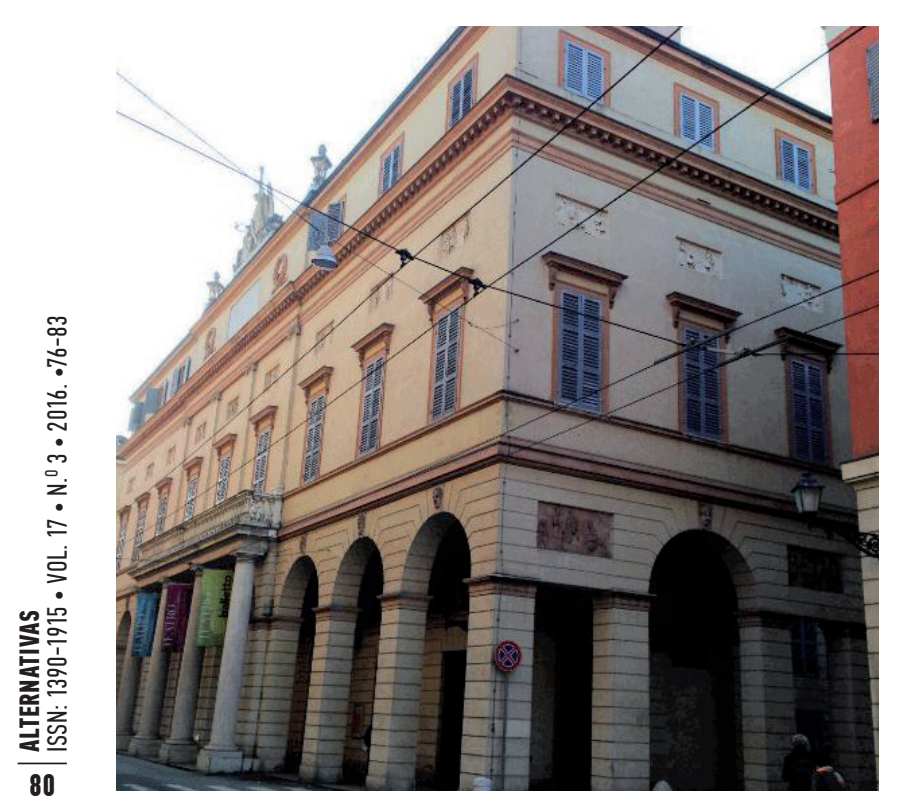

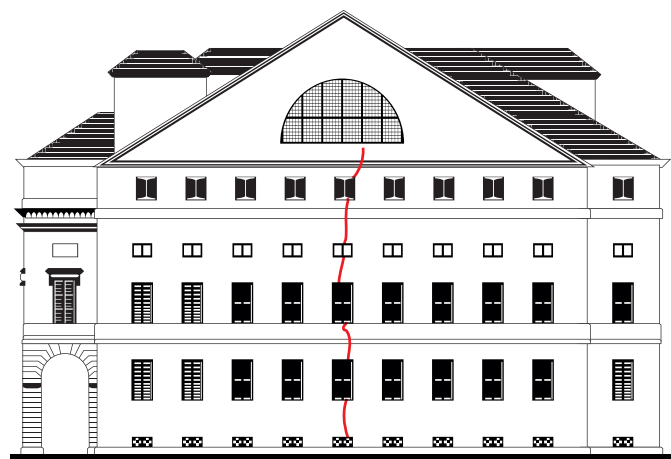

Figure 4. Pavarotti Theatre: a) main façade, b) rear façade (seismic cracks depicted).

The local mechanism object of the study is the collapse of the rear façade wall (figure. 4 and 5a) due to the formation of three horizontal cylindrical hinges (no decks are present because there is located the volume of stage):

(1) C1: at the bottom level of lowest row of windows; (2) C2: at the top level of highest row of windows; (3) C3: its position is the unknown of the problem.

In figure. $5 \mathrm{~b}$ the kinematic scheme of the local mechanism is shown.
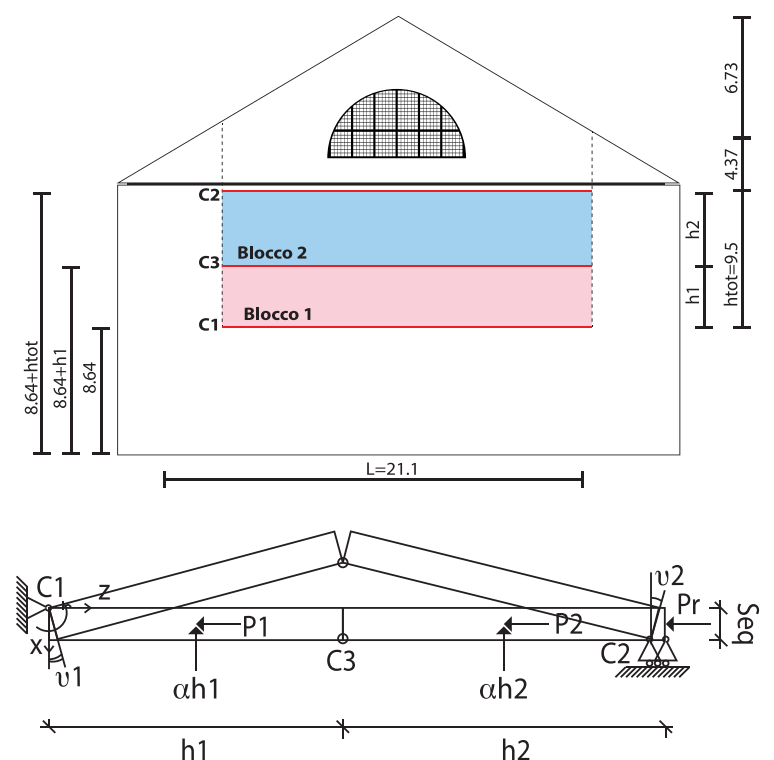

Figure 5. (a) Local mechanism analysed and (b) magnification of the portion of façade involved in the mechanism: the kinematic scheme.

\section{TABLE 5. RESULTS OF LINEAR KINEMATIC ANALYSIS FOR REINFORCED} STRUCTURE.

\begin{tabular}{rrrr}
$\mathbf{A}_{0}$ & $\mathbf{A}_{0}^{*}$ & $\mathbf{A}_{D}^{*}$ & $R$ \\
0.647 & $0.479 \mathrm{~g}$ & $0.322 \mathrm{~g}$ & 1.49 \\
\hline
\end{tabular}

Even if the structure is safe against this mechanism, a design of reinforcement can be made to reduce the spectral acceleration (demand). One possibility is to insert 4 GeoSteel600 strips, 2 for each side of the wall, with connectors (figure. 6a and $6 \mathrm{~b}$ ), to contrast the opening of the wall near 
the intermediate hinge. The connectors are placed at a distance of $25 \mathrm{~cm}$ one from each other all along the strips. The detachment force of the strip, the maximum force of the connectors and the effective length are the same as in previous example.
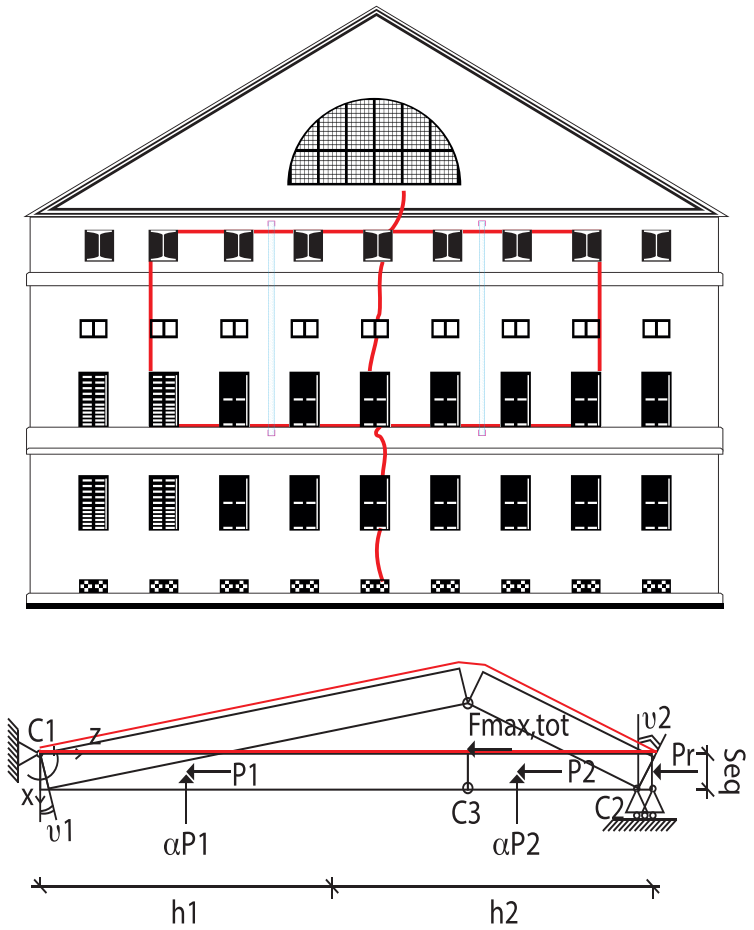

Figure 6. (a) Design of the reinforcement on the front wall and (b) magnification of the portion of façade involved in the mechanism: the static scheme with reinforcement.

In table 5, the results of the reinforced structure are shown.

TABLE 5. RESULTS OF LINEAR KINEMATIC ANALYSIS FOR REINFORCED STRUCTURE

\begin{tabular}{rrrr}
$\mathbf{A}_{\mathbf{0}}$ & $\mathbf{A}_{\mathbf{0}}^{*}$ & $\mathbf{A}_{D}^{*}$ & $R$ \\
0.651 & $0.482 \mathrm{~g}$ & $0.289 \mathrm{~g}$ & 1.67 \\
\hline
\end{tabular}

\section{RENO CENTESE BELL TOWER}

The bell tower of Reno Centese is located in the municipality of Cento, province of $\mathrm{Fe}^{-}$ rrara, Italy [13]. Starting from its base, the tower is made up of 1) a main prism-shaped corpus (square section shape) including the basement, with small circular openings (windows), 2) a belfry and 3) a spire (figure 7). The tower is $29.25 \mathrm{~m}$ high with walls characterized by a constant thickness (in the trunk) about $0.50 \mathrm{~m}$

An earthquake of 5.9 magnitude occurred in the provinces of Ferrara, Modena and Bologna during the night of 20th May 2012, causing severe damages to many masonry towers and bell towers [7]. Over the successive two months, further seismic events occurred with another six events of a magnitude greater than 5. At the time of the May 2012 earthquake, the tower of Reno Centese was undergoing a "cosmetic" restoration so scaffolding was in place. A severe inclined crack was due to an out of plane rotation of the upper part of the bell tower, which caused successive sliding, two dislocations after shock appeared and experts determined that the tower was in risk of collapse (figure 8). For this reason, a "red area" was delimited around the tower and all activities inside the area were suspended.

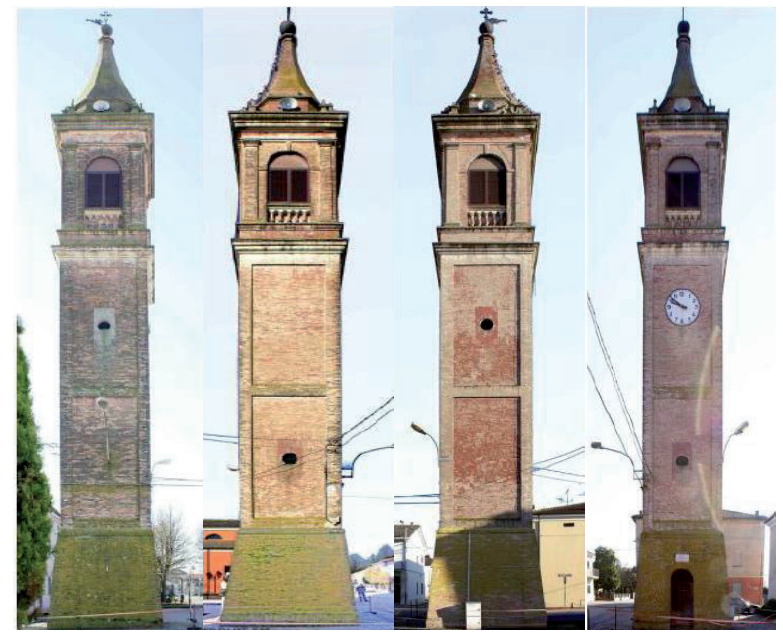

Figure 7. The bell tower of Reno Centese.
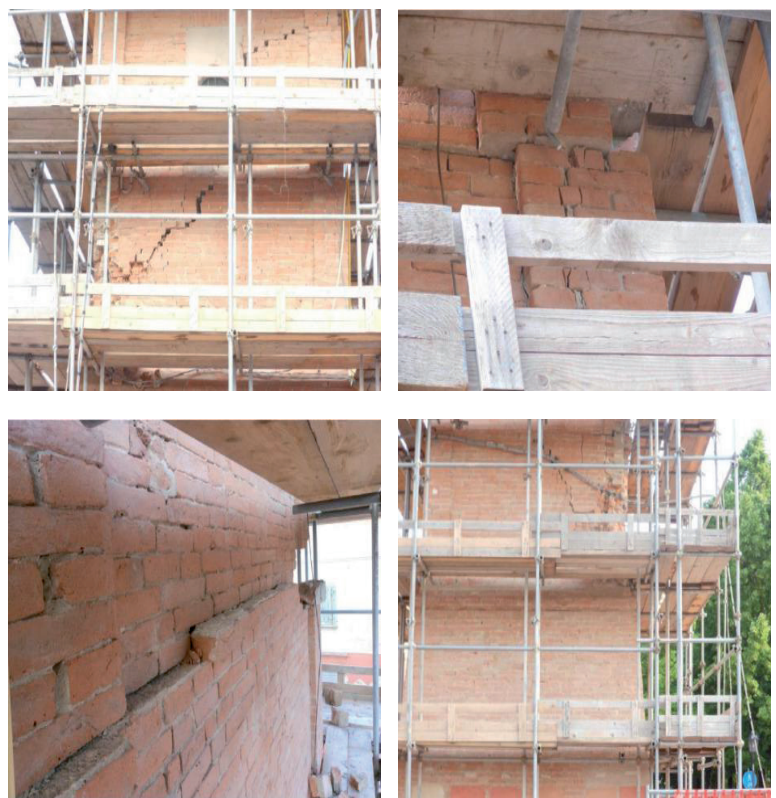

Figure 8. Main damage resulting from the May 2012 earthquake in Emilia: a) diagonal crack (west side), b) dislocation $A(20 \mathrm{~cm})$, c) dislocation $B(6 \mathrm{~cm})$, d) cracks (north side). 




Figure 9. Propagation of crack due to bending.

After the propagation of the cracks due to bending, the bell tower is composed by two blocks, figure 8: the first one in the bottom part containing the basement and the first part of the trunk, the second block is made by the second part of the trunk, the belfry and the spire.

In order to study the capacity curve, an ideal 3D tower (figure 9), is used as simplified model.

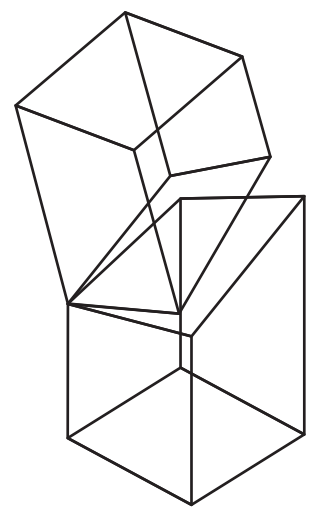

Figure 10. Ideal 3D of tower.

On the bell tower, the propagation of the cracks due to recent earthquake follows two different directions: on the north and west sides the angle of inclination is about $\theta=37^{\circ}$, while on the south and east sides the angle of inclination is about $\phi=3^{\circ}$. At this stage, the kinematic chain is defined so it is possible to evaluate the load multiplier that corresponds to the activation of the mechanism (Eq. 1).

It is important noting at each step, corresponding to an increment of rotation equal to 1 degree with respect to the previous step; the new position of the centroid is calculated.

In figure 10, the collapse multiplier function of the new position of the centroid is reported.



Figure 11. Tower Reno Centese. Collapse multiplier.

By using Eqs. 2 and 3, it is possible to calculate the spectral acceleration and the spectral displacement and, in the end, the capacity curve, figure 11 .

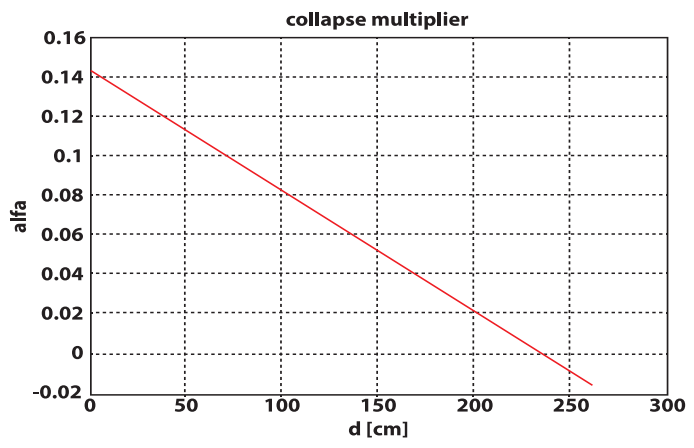

Figure 12. Capacity curve of Reno Centese Tower.

By using the linear kinematic approach, the tower is satisfied against near collapse performance state but not for the life safety performance state. Considering non-linear kinematic approach the bell tower is safe against collapse for life safety performance state

$$
\left(d_{u}^{*} \geq \Delta d\left(T_{s}\right), 82.44 \mathrm{~cm} \geq 15.1463 \mathrm{~cm}\right)
$$

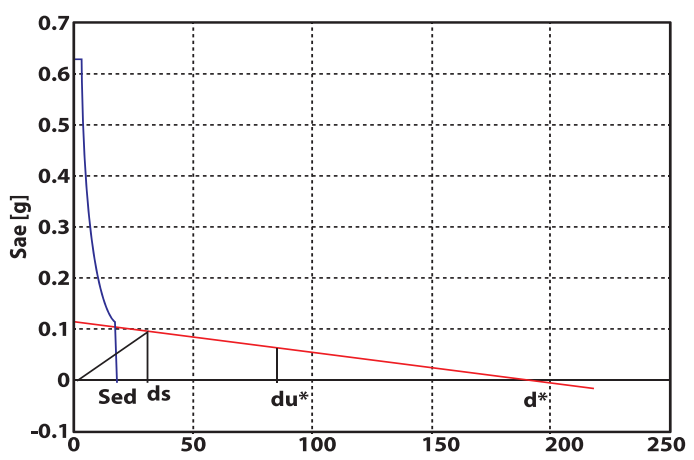

Figure 13. Graphical representation of the non-linear kinematic verification (spectral acceleration vs.spectral displacements).

CONCLUSIONS

In the present study some problems in the application of different procedures to evaluate 
the vulnerability of existing monuments are discussed. The different procedures, also recommended by national and international standards, sometimes give different responses, then the engineer involved in the judgement has to utilize also personal convictions. In effect, the use of several not objective coefficients in the procedure drives to a not unique answer in terms of safety evaluation. The level of protection can be greater than minimum required by national standards covering the uncertainty of coefficients (FC: Confidence Factor, q: behaviour factor, etc...) choice. Regarding the procedure via local mechanisms, some aspects merit consideration: the interaction of blocks with surroundings structures that are difficult

\section{REFERENCES}

1. Istruzioni per l'applicazione delle Norme Tecniche (2008) (in Italian), http://www.rete.toscana. it/sett/pta/sismica/classificazioni/index.htm.

2. Casacci S., Di Tommaso A., Gentilini C., Reinforced Repointing Technique to Strengthen Masonry, 2nd International Conference on Protection of Historical Construction (PROHITECH 2014), Antalya, Turchia, 7-9 May 2014.

3. Casacci S., Di Tommaso A., Centilini C., Crack propagation in Compression and Mounted Arrestors, Key Engineering Materials 624, 595602, 2015.

4. Curti E., Podestà S., Resemini S., (2008), Meccanismi di collasso locali: analisi cinematica non lineare. Edifici in muratura. Progettazione degli interventi post-sisma, Volume edited by Lemme, A. Martinelli, S. Podestà.

5. Decreto Ministeriale Italiano (DM 14 Cennaio 2008), Norme Tecniche per le Costruzioni (in Italian).

6. Di Tommaso A., Lancellotta R., Focacci F., Romaro F., Seismic capacity of the Chirlandina Tower in Modena, Italy, International Conference on Structural Analysis of Historical Constructions (SAHC 2012), Wroclaw, Poland, 15-17 October 2012.

7. Di Tommaso A., Casacci S., Sopravvivenza di torri e campanili in ambiente sismico, Seminario Internazionale sull'Evoluzione nella sperimentazione per le costruzioni (CIAS 2013), Creta, Grecia, 18-25 Maggio 2013.

8. Di Tommaso A., Focacci F., Strengthening Historical Monuments with FRP: a Design Crieria Review, Proceedings Intern. Conference "Composites in Construction: a reality", Capri, Italy,July 2001.

9. Barbieri A., Di Tommaso A., Focacci F., AFRP connector to prevent brittle debonding in FRP to evaluate (see: the roof for upper blocks,...). For the "analytical" evaluation of the mechanisms sometimes the lability and its evolution is not clear. On the side of efficacy of strengthening with composites strips FRCM, when two lips of masonry have relative movements in Mode II (FM, sliding, see [8]) the contrast can be done essentially by strip with connections (mainly mechanical connectors, see [9]) and the evaluation of their mode of operation and analytical modelling is not covered by standard formulation. Among the mechanisms regarding towers we should include that involving soil [6]; here the analysis is not complete for each structure but only one mechanism has been taken into account.

strengthened RC beams, Proceedings 2nd convegno fib, Napoli, 5-8 June 2006

10. Di Tommaso A., Focacci F., Mantegazza G., Gatti A., FRCM vs FRP composites to strengthen RC beams: a comparative analysis, FRPRCS-8, University of Patras, Patras, Greece July 16-18, 2007

11. Fajfar P., (1999), Capacity spectrum method based on inelastic demand spectra. Earthquake Engineering and Structural Dynamics, 28, pp. 979-993.

12. Fajfar P., (2000), A nonlinear analysis method for performance-based Seismic design.. Earthquake Spectra, 16(3), pp. 573-592.

13. Franceschini G., Meccanismi non lineari di collasso, tesi di Laurea magistrale, Relatore: Di Tommaso A., Unibo, a.a. 2012-2013.

14. Freeman S. A., (1978), Prediction of response of concrete buildings to severe earthquake motion, Douglas Mc henry International Symposium on Concrete and Concrete Structures, ACI SP-55, American Concrete Institute, Detroit, pp. 589-605.

15. Freeman S. A., (1998), Development and use of capacity spectrum method, Proceeding Sixth U.S: National Conference on Earthquake Engineering, Earthquake Engineering Research Inst., Oakland California.

16. Heyman J., (1982), TheStoneSkeleton: Structural Engineering of Masonry Architecture, Cambridge University Press.

17. Lazzarini L., Rinforzi di murature con compositi FRCM. Caso di studio: Teatro Pavarotti di Modena, tesi di Laurea magistrale, Relatore: Di Tommaso A., Unibo a.a. 2012-2013.

18. Ordinanza Presidenza del Consiglio dei Ministri Italiano, n. 3274 (20 Marzo 2003), Allegato 2 Norme tecniche per il progetto, la valutazione e l'adeguamento sismico degli edifici. 